\title{
Modelling long-term impacts of mountain pine beetle outbreaks on merchantable biomass, ecosystem carbon, albedo, and radiative forcing
}

\author{
Jean-Sébastien Landry ${ }^{1,6}$, Lael Parrott ${ }^{2}$, David T. Price ${ }^{3}$, Navin Ramankutty ${ }^{4}$, and H. Damon Matthews ${ }^{5}$ \\ ${ }^{1}$ Department of Geography, McGill University, Montréal, Canada \\ ${ }^{2}$ Earth and Environmental Sciences and Biology, Irving K. Barber School of Arts and Sciences, \\ University of British Columbia, Kelowna, Canada \\ ${ }^{3}$ Natural Resources Canada, Canadian Forest Service, Northern Forestry Centre, Edmonton, Canada \\ ${ }^{4}$ Liu Institute for Global Issues and Institute for Resources, Environment, and Sustainability, \\ Universityof British Columbia, Vancouver, Canada \\ ${ }^{5}$ Department of Geography, Planning and Environment, Concordia University, Montréal, Canada \\ ${ }^{6}$ Currently at the Department of Geography, Planning and Environment, Concordia University, Montréal, Canada
}

Correspondence to: Jean-Sébastien Landry (jean-sebastien.landry2@mail.mcgill.ca)

Received: 22 April 2016 - Published in Biogeosciences Discuss.: 28 April 2016

Revised: 18 July 2016 - Accepted: 7 September 2016 - Published: 22 September 2016

\begin{abstract}
The ongoing major outbreak of mountain pine beetle (MPB) in forests of western North America has led to considerable research efforts. However, many questions remain unaddressed regarding its long-term impacts, especially when accounting for the range of possible responses from the non-target vegetation (i.e., deciduous trees and lower-canopy shrubs and grasses). We used the Integrated BIosphere Simulator (IBIS) process-based ecosystem model along with the recently incorporated Marauding Insect Module (MIM) to quantify, over 240 years, the impacts of various MPB outbreak regimes on lodgepole pine merchantable biomass, ecosystem carbon, surface albedo, and the net radiative forcing on global climate caused by the changes in ecosystem carbon and albedo. We performed simulations for three locations in British Columbia, Canada, with different climatic conditions, and four scenarios of various coexisting vegetation types with variable growth release responses. The impacts of MPB outbreaks on merchantable biomass (decrease) and surface albedo (increase) were similar across the 12 combinations of locations and vegetation coexistence scenarios. The impacts on ecosystem carbon and radiative forcing, however, varied substantially in magnitude and sign, depending upon the presence and response of the non-target vegetation, particularly for the two locations not subjected to growing-
\end{abstract}

season soil moisture stress; this variability represents the main finding from our study. Despite major uncertainty in the value of the resulting radiative forcing, a simple analysis also suggested that the MPB outbreak in British Columbia will have a smaller impact on global temperature over the coming decades and centuries than a single month of global anthropogenic $\mathrm{CO}_{2}$ emissions from fossil fuel combustion and cement production. Moreover, we found that (1) outbreak severity (i.e., per-event mortality) had a stronger effect than outbreak return interval on the variables studied, (2) MPBinduced changes in carbon dynamics had a stronger effect than concurrent changes in albedo on net radiative forcing, and (3) the physical presence of MPB-killed dead standing trees was potentially beneficial to tree regrowth. Given that the variability of pre-outbreak vegetation characteristics can lead to very different regeneration pathways, the four vegetation coexistence scenarios we simulated probably only sampled the range of possible responses. 


\section{Introduction}

The mountain pine beetle (MPB; Dendroctonus ponderosae Hopkins) is an insect native to forests of western North America, from northern Mexico to British Columbia, Canada (Safranyik and Carroll, 2006). Outbreaks of this bark beetle are characterized by high stand-level mortality of the target species, primarily lodgepole pine (Pinus contorta var. latifolia), but also other pines and, occasionally, other genera (NRCan, 2012). The MPB outbreak that started at the end of the previous century has reached an unprecedented level of documented severity, particularly in British Columbia where 18.1 Mha of forests have been affected (British Columbia, $2012 \mathrm{~b}$ ) and more than half of the merchantable pine volume has been killed (Walton, 2013).

Forests generally appear to recover well following MPB outbreaks (Axelson et al., 2009; Kashian et al., 2011; Hansen, 2014; Alfaro et al., 2015), which have recurred in western North America for thousands of years (Brunelle et al., 2008). However, forest managers face the decision of whether to proceed with salvage logging of MPB-killed dead standing trees (DSTs) and how best to do it (Griesbauer and Green, 2006; Bowler et al., 2012; Amoroso et al., 2013; Hawkins et al., 2013; Mathys et al., 2013; Landry and Ramankutty, 2015). MPB impacts also go beyond timber losses by modifying ecosystem carbon storage, thereby possibly affecting the ongoing climate change. The recent MPB outbreak has been estimated to decrease ecosystem carbon storage (cumulative values) by $270 \mathrm{Tg} C$ between 2000 and 2020 in British Columbia (Kurz et al., 2008), by $580 \mathrm{Tg} \mathrm{C}$ between 1999 and 2050 in British Columbia (Arora et al., 2016), and by $15-26 \mathrm{Tg} C$ between 2000 and 2009 in the western United States (Ghimire et al., 2015), the last value increasing to 19$35 \mathrm{Tg} \mathrm{C}$ when including mortality from other bark beetles.

Recent reviews have identified various lingering knowledge gaps limiting the understanding of ecological and climatic effects caused by outbreaks of MPB and other forest insects (Liu et al., 2011; Seidl et al., 2011; Hicke et al., 2012a; Landry and Ramankutty, 2015). First, the mortality of many large trees often causes a growth release of the surviving non-target species and smaller host trees generally avoided by the MPB, which can alter the competition balance among the plant types present (Romme et al., 1986; Heath and Alfaro, 1990; Stone and Wolfe, 1996; Axelson et al., 2009; Amoroso et al., 2013; Hawkins et al., 2013; Hansen, 2014; Alfaro et al., 2015; Campbell and Antos, 2015). This growth release likely explains why field-based studies using the eddy covariance method have found the forest carbon balance to be more resilient than expected during an MPB outbreak or for close to a decade afterwards (Bowler et al., 2012; Brown et al., 2012; Reed et al., 2014). Therefore, modelling studies should allow for the possibility of a compensatory response from the surviving vegetation, including lower-canopy shrubs and grasses. Second, there is a need for more studies assessing the range of responses to different outbreak mortality levels and return intervals under the same background conditions, because comparisons performed across forest types and climates can be misleading. Third, the recurrence of MPB outbreaks calls for a long-term perspective going beyond a single mortality event. Fourth, the impact of the physical presence of MPB-killed DSTs on local exchanges of energy and water as well as the influence of these modified exchanges on carbon cycling have hitherto not been studied. Fifth, the climatic effects of MPB outbreaks are not limited to the carbon cycle, as the post-outbreak fall of DST needles and stems increases the reflection of incoming solar radiation, especially over seasonally snow-covered forests (Bright et al., 2013; Vanderhoof et al., 2014). In the only study to date aiming to quantify the net global climatic impact of MPB outbreaks, this albedo-induced cooling was estimated to be stronger than the warming from reduced ecosystem carbon storage (O'Halloran et al., 2012).

The main objective of our study was to use a modelling approach to evaluate the impacts of MPB outbreaks on four variables relevant to the forestry sector, land-atmosphere exchanges of carbon and energy, and global climate change, while explicitly addressing the five knowledge gaps identified above. Although more uncertain than empirical studies, process-based modelling approaches can provide a longerterm perspective on the impacts of MPB outbreaks and help assess interactions among several factors. Our purpose was not to forecast stand-level forest attributes (e.g., species-level basal area) but rather to contrast responses for very different scenarios about the presence and response of "non-target vegetation", which consisted of deciduous trees and lowercanopy shrubs and grasses that are never targeted by the MPB. Similarly, we did not account for all the factors affecting MPB population dynamics because we imposed idealized outbreak regimes, seeking here to provide initial insights on how impacts varied as a function of outbreak severity and return interval (e.g., Dietze and Matthes, 2014).

\section{Methods}

\subsection{Overview}

Our approach involved a set of different scenarios of coexistence between the MPB-targeted trees and non-target vegetation types; for each of these scenarios, we compared, over 240 years and for three locations in British Columbia, the impacts of various MPB outbreak regimes. In each instance, we included the explicit representation of interactions between MPB-killed DSTs and the carbon, energy, and water cycles.

\subsection{Modelling the effects of MPB mortality}

We used the recently developed Marauding Insect Module (MIM) incorporated within the Integrated BIosphere Simulator (IBIS) to simulate the effects of insect outbreaks. Here, 
we provide an overview of IBIS-MIM and refer readers to Landry et al. (2016) for more details.

The IBIS global ecosystem model was originally developed to estimate, within a single and consistent modelling framework, the land-atmosphere exchanges of carbon, energy, water, and momentum required by climate models, while simulating how vegetation phenology and spatial distribution respond to climate (Foley et al., 1996; Kucharik et al., 2000). IBIS represents coexisting upper (trees) and lower (shrubs and grasses) vegetation canopies as well as various soil and snow layers. The simulated exchanges of carbon, energy, and water depend upon the state of both canopies and the soil, including snow when present. Vegetation diversity is represented through various plant functional types (PFTs) characterized by different climatic constraints and parameters related to physiology, carbon dynamics, and energy exchanges. Photosynthesis and autotrophic respiration are typically computed on an hourly time step as a function of input climatic conditions. Competition balance and vegetation changes are determined at the end of each year based on the annual carbon balance of each PFT, except for the leaf phenology of deciduous PFTs, which is updated daily. For each PFT that can exist in the grid cell based on prevailing climatic conditions, leaf area index (LAI) cannot become lower than a very small, but non-zero, value; if a PFT undergoes $100 \%$ mortality in a grid cell (e.g., as occurred with our Peak regime; see Sect. 2.3), this "seed" LAI can therefore initiate regeneration. IBIS does not simulate establishment of many individuals for the same PFT in a grid cell. Annual litterfall is divided into daily transfers to soil, where carbon decomposition is modelled as a function of microbial biomass, soil temperature, and moisture. IBIS results compare relatively well with empirical data over large regions and several field sites, including in Canada (Foley et al., 1996; Delire and Foley, 1999; Kucharik et al., 2000; Lenters et al., 2000; El Maayar et al., 2001, 2002; Kucharik et al., 2006).

MIM was designed to simulate the effects of insect outbreaks within process-based ecosystem models similar to IBIS (Landry et al., 2016). MIM prescribes, at a daily time step, the direct insect-caused vegetation damage (i.e., defoliation and/or mortality), an approach that is similar to the "pathogen and insect pathways" from Dietze and Matthes (2014). The resulting impacts on vegetation dynamics and land-atmosphere exchanges of carbon, energy, and water are estimated by the supporting ecosystem model as a function of the post-outbreak state of the vegetation. MIM currently represents the effects of vegetation damage caused by outbreaks of three insect functional types (IFTs): broadleaf defoliators, needleleaf defoliators, and bark beetles. The bark beetle IFT used here was parameterized based on MPB-caused mortality of lodgepole pine. When a MPB outbreak occurs, mortality is assumed to begin on 1 August and increases linearly over 50 days (Landry et al., 2016) until reaching the userprescribed annual mortality level for the specific year (see
Table 1. Input climate data and soil texture for the three locations.

\begin{tabular}{lrrr}
\hline Element & Northern & Central & Southern \\
\hline Temperature $\left({ }^{\circ} \mathrm{C}\right)$ & & & \\
Annual & 0.7 & 0.8 & 2.5 \\
Dec-Feb & -11.3 & -8.8 & -6.8 \\
Mar-May & 0.9 & 0.4 & 2.0 \\
Jun-Aug & 11.9 & 9.9 & 12.0 \\
Sep-Nov & 1.0 & 1.4 & 2.7 \\
Precipitation & & & \\
(mm day -1$)$ & & & \\
Annual & 1.7 & 1.6 & 1.6 \\
Dec-Feb & 2.0 & 1.9 & 2.3 \\
Mar-May & 1.2 & 1.1 & 1.4 \\
Jun-Aug & 1.9 & 1.6 & 1.3 \\
Sep-Nov & 1.8 & 1.7 & 1.6 \\
Soil texture & Sandy loam & Loam & Sandy loam \\
Sand (\%) & 65 & 42 & 65 \\
Silt (\%) & 25 & 40 & 25 \\
Clay (\%) & 10 & 18 & 10 \\
\hline
\end{tabular}

Section 2.3). Killed trees become DSTs that interact with the exchanges of energy and water (e.g., absorbing solar radiation) but do not transpire or perform photosynthesis. DST carbon is gradually transferred to litter based on a predefined schedule: at year end for fine roots, over the 3 years following the year of mortality for needles, and, after a 5-year delay period, over 20 years for stem and coarse roots (Landry et al., 2016). IBIS then subdivides these annual amounts into daily transfers to soil.

IBIS-MIM results after a simulated MPB outbreak generally agreed with previous studies (Landry et al., 2016). The only bias identified in that previous assessment of IBIS-MIM consisted of a lower snow depth/amount following MPB mortality vs. the no-outbreak control, contrary to the conclusion of most - but not all - previous studies. This bias likely resulted from overestimation by IBIS of heat storage within tree stems (Pollard and Thompson, 1995; El Maayar et al., 2001), including DSTs. IBIS-MIM might therefore underestimate the length of the snow cover season in MPB-attacked stands, thereby underestimating the consequent increases in springtime albedo and reflected solar radiation. This possible bias seems unlikely to be serious for the current study, because (1) areal snow coverage, which matters more for albedo than snow depth/amount, was the same for the outbreak and control results during most of the snow cover season; and (2) the generally earlier and faster snowmelt caused by MPB outbreaks (Pugh and Small, 2012; Mikkelson et al., 2013) is consistent with IBIS-MIM results.

\subsection{Simulation design}

IBIS requires input data for soil texture and climatic variables related to temperature, humidity (including precipitation and cloud cover), and wind speed. For all variables, including the 


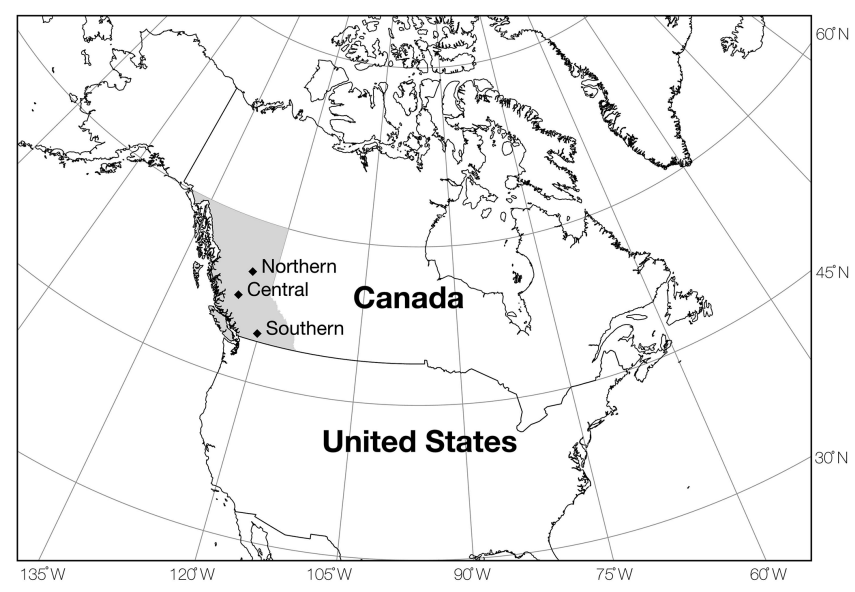

Figure 1. Three locations studied; the province of British Columbia is shaded.

ones provided in Table 1, we used the same input data as Landry et al. (2016): the mean 1961-1990 atmospheric $\mathrm{CO}_{2}$ level, gridded 1961-1990 monthly mean data for climate (New et al., 1999), and survey data from versions 2.1 and 2.2 of the Soil Landscapes of Canada for soil (http://sis.agr. gc.ca/cansis/nsdb/slc/index.html). Note that contrary to gap models, IBIS does not have an intrinsic spatial resolution; however, as the computation of radiative forcing requires a specific area (see Appendix A), we used a nominal area of 1 ha here. Although we did not assess the effect of climate change, seeking to first understand the ecosystem responses within a stable climate regime, we considered the effect of varying climatic conditions by studying three locations in British Columbia, henceforth designated as northern, central, and southern (Fig. 1). These three locations have witnessed substantial MPB mortality since 2000 (Walton, 2013) under different climatic conditions (Table 1). The southern location is warmer than the central and northern locations. These last two locations have similar mean annual temperature, but the northern location has warmer summers and colder winters. Annual precipitation is similar in all locations, but summer rainfall is much lower in the southern location and results in drier conditions during the growing season.

We divided the simulations into four groups of different vegetation coexistence scenarios (Table 2). Five IBIS PFTs can coexist at the three locations considered here: the needleleaf evergreen (NE) trees targeted by MPB, broadleaf deciduous (BD) trees (e.g., trembling aspen; Populus tremuloides Michx.), and evergreen shrubs, cold-deciduous shrubs, and $\mathrm{C}_{3}$ grasses in the lower canopy. The NEonly scenario allowed only NE trees and thus did not account for the possible response of the non-target vegetation. The NE-LC scenario allowed for the coexistence of $\mathrm{NE}$ trees and lowercanopy PFTs, but excluded BD trees. Note that in IBIS, coexisting PFTs compete for the same incoming solar radiation and soil water instead of being segregated into inde-
Table 2. The four different scenarios simulated for the coexistence of plant functional types (PFTs). NE is needleleaf evergreen tree (i.e., the target PFT); LC is lower canopy (i.e., the sum of evergreen shrubs, cold-deciduous shrubs, and $\mathrm{C}_{3}$ grasses); $\mathrm{BD}$ is broadleaf deciduous tree.

\begin{tabular}{ll}
\hline Scenario & PFTs allowed \\
\hline NEonly & NE \\
NE-LCcons & NE and LC, with constant LC biomass \\
& from the first outbreak onwards \\
NE-LC & NE and LC \\
AllPFT & NE, LC, and BD \\
\hline
\end{tabular}

pendent sub-grid tiles as in many similar models, so that tree PFTs actually shade the underlying lower canopy. The NE-LCcons scenario was similar to NE-LC except that the total biomass of the lower canopy was kept constant from the year of the first MPB outbreak onwards. Consequently, the lower canopy could increase its net primary productivity (NPP, in $\mathrm{kg} \mathrm{C} \mathrm{m}^{-2} \mathrm{yr}^{-1}$ ) following MPB mortality (e.g., due to higher light penetration), but the additional productivity was transferred to litterfall so that the lower canopy was unable to grow and expand, thereby preventing further increases in productivity. The purpose of this constraint was to account for the effect of vegetation growth limitations not included in IBIS, such as nutrient availability. Finally, the AllPFT scenario allowed the five PFTs to freely compete throughout all years. Previous modelling studies quantifying MPB impacts on $C_{\text {eco }}$ or net ecosystem productivity (NEP, in $\mathrm{kg} \mathrm{C} \mathrm{m}^{-2} \mathrm{yr}^{-1}$ ) (Kurz et al., 2008; Edburg et al., 2011; Ghimire et al., 2015; Arora et al., 2016) have resorted to NEonly-type approaches that did not account for the possible growth release of the non-target vegetation.

We performed 12 sets (three locations and four coexistence scenarios) of five independent simulations; note that all simulations at a given location had the exact same weather. For a given set, the five independent simulations branched from the same 400-year spin up (which was sufficient for carbon pools to stabilize; see Landry et al. (2016) for more details) and consisted of (1) a no-outbreak control run; (2) a single $100 \%$ MPB mortality event occurring during year 1 after the spin up, used to assess the theoretical maximum impacts and designated the Peak regime; (3) a regime of periodic single-year MPB outbreaks, also starting in year 1 , with a mortality level of $16 . \overline{6} \%$ at return intervals of 20 years, designated the Small regime; (4) similar to Small, but with a single-year mortality level of $33 . \overline{3} \%$ at return intervals of 40 years, designated the Medium regime; and (5) similar to Small and Medium, but with a single-year mortality level of $50.0 \%$ at return intervals of 60 years, designated the Large regime. We simulated a spatially homogeneous distribution of MPB-killed trees, based on the observation that MPB mortality was spatially more regular than the underlying distribution of trees in a 0.25 ha plot (Kashian et al., 
2011) and to avoid the complications of introducing sub-grid spatial heterogeneity in IBIS. All simulations were continued for 240 years after the spin up, for a total of 640 years. Note that over these last 240 years, the mean mortality was $0.8 \overline{3} \% \mathrm{yr}^{-1}$ for the three periodic regimes (e.g., $16 . \overline{6} \%$ mortality every 20 years for Small), thereby allowing the effect of outbreak severity vs. return interval to be compared for the same mean mortality, but was only $0.41 \overline{6} \% \mathrm{yr}^{-1}$ for the Peak regime (i.e., a single $100 \%$ mortality event over 240 years). We simulated single-year mortality events instead of manyyear outbreaks for two reasons. First, we wanted to focus on long-term results and a previous study with a model similar to IBIS found that, for the same level of total mortality occurring over 1,5 , or 15 years, differences in NEP became very small 25 years after the outbreaks (Edburg et al., 2011). Second, simulating a multiyear outbreak would raise the issues of its length and precise unfolding over consecutive years, introducing other complicating factors to our experimental setup that already considers the combination of three locations, four coexistence scenarios, and four outbreak regimes.

\subsection{Response variables}

We studied four variables: lodgepole pine merchantable biomass $\left(B_{\text {merch}}\right.$, in $\left.\mathrm{kg} \mathrm{C} \mathrm{m}^{-2}\right)$, ecosystem carbon $\left(C_{\mathrm{eco}}\right.$, in $\mathrm{kg} \mathrm{C} \mathrm{m}^{-2}$ ), surface albedo ( $\alpha$, unitless), and radiative forcing $\left(\mathrm{RF}\right.$, in $\left.\mathrm{W} \mathrm{m}^{-2}\right)$. $B_{\text {merch }}$ is highly relevant for the forestry sector, as it indicates the amount of lodgepole pine having commercial value. Note that, in the AllPFT scenario, BD trees (e.g., trembling aspen) could also have some commercial value, but we intentionally limited $B_{\text {merch }}$ to lodgepole pine due to the major commercial importance of this species in British Columbia. $C_{\text {eco }}$ goes beyond timber and accounts for all the carbon contained in live and dead pools including the soil, so that changes in $C_{\text {eco }}$ directly affect atmospheric $\mathrm{CO}_{2}$ levels. Changes in $\alpha$ affect energy exchanges, with increases in $\alpha$ implying a cooling influence on the global climate. Finally, RF is used to assess the net impact of different perturbations on the global mean atmospheric surface temperature, without performing simulations with climate models (Myhre et al., 2013). In this study, the net RF (indicating warming if $\mathrm{RF}>0$, cooling if $\mathrm{RF}<0$ ) following MPB outbreaks was the sum of the radiative forcing from changes in atmospheric $\mathrm{CO}_{2}$ and $\alpha$. Unlike the other variables, $\mathrm{RF}$ is defined as a change between two different states; hence, RF results cannot be provided on a relative change (\%) basis but must be absolute values for a given outbreak area. We stress that even if MPB impacts were simulated for a nominal area of 1 ha, the RF results we report are, by definition, for the net effect on global climate. We explain in Appendix A how we used IBIS output to compute $B_{\text {merch }}$ and RF.

\subsection{Simplified analysis of maximum global climatic impact}

Our simulation design was too simple to allow for a precise estimate of the global climatic impact from the MPB outbreak in British Columbia, but we used our RF results to bound the maximum value of this net warming or cooling impact. To do so, we identified among all our Peak simulations the two instances that led to the most extreme (positive and negative) annual RF values. We then recomputed these RF trajectories for an area of 18.1 Mha, which is the total area affected by the MPB outbreak (British Columbia, $2012 b$ ). Finally, we determined the value of a single pulse of actual (positive RF) or avoided (negative RF) fossil fuel $\mathrm{CO}_{2}$ emissions that would invariably have, throughout the 240 years, a stronger radiative forcing than the MPB-caused RF (see Appendix A). This approach likely overestimated the maximum annual impact of MPB on the global climate for three reasons. First, not all area affected by MPB suffered $100 \%$ mortality as prescribed in Peak. Second, the singleyear Peak mortality led to stronger extreme RF values compared to a gradual increase and decrease of the outbreak over many years. Third, the amount and composition of non-target vegetation are highly variable among MPB-attacked stands (Axelson et al., 2009; Amoroso et al., 2013; Hawkins et al., 2013; Pelz and Smith, 2013; Alfaro et al., 2015; Campbell and Antos, 2015) and this variability appears consequential for RF (see Sect. 3); hence the RF response from the same vegetation coexistence scenario was unlikely representative of the mean response over the entire area affected.

\section{Results}

\subsection{Comparison to previous studies}

IBIS-MIM results following a MPB outbreak have already been found to agree with results from 38 field-, satellite-, and model-based studies for 28 variables related to vegetation dynamics and the exchanges of carbon, energy, and water, over daily to multiannual timescales (Landry et al., 2016). That previous assessment also provided time-sincedisturbance NPP results for different PFTs under the NELCcons scenario. Here we performed an additional assessment of IBIS-MIM, comparing its results for different variables related to the carbon cycle and for $\Delta \alpha$ to previous studies (see Tables S1-S2 in the Supplement). We restricted these comparisons to empirical studies that included control stands, except for the modelling study of Arora et al. (2016) that used a model similar to IBIS-MIM under a NEonlytype setting and provided results for one grid cell close to our central location. Given the differences in locations, cumulative mortality levels, and temporal patterns of mortality, IBIS-MIM agreed reasonably well with previous stud- 


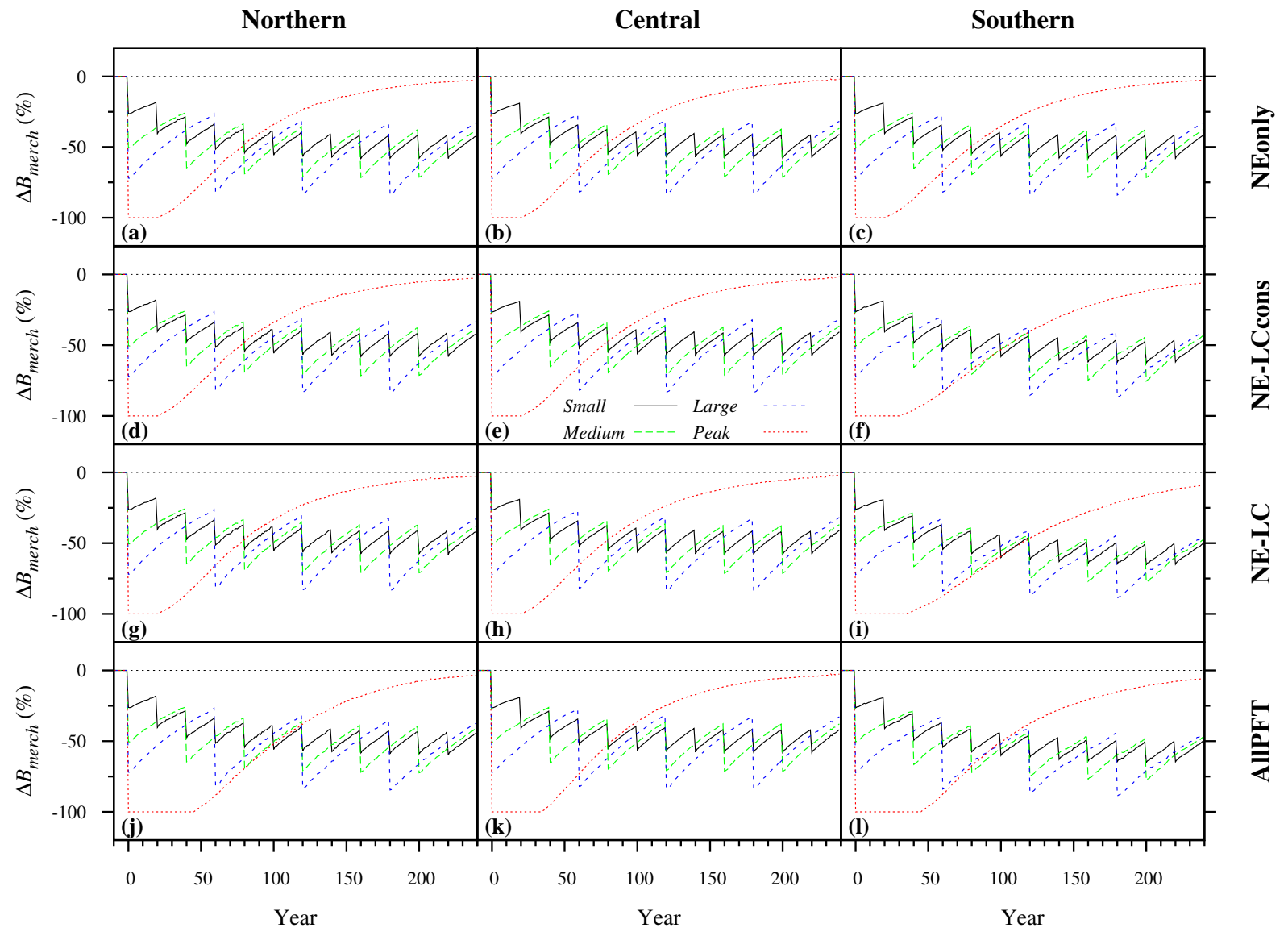

Figure 2. Transient effect of the different MPB outbreak regimes on lodgepole pine merchantable biomass $\left(B_{\text {merch }}\right)$ compared with the no-outbreak control run (first outbreak occurred in year 1). The columns correspond to the three locations (Fig. 1) and the rows to the four vegetation coexistence scenarios (Table 2). Control values differed among locations and vegetation coexistence scenarios, so the same relative change (in \%) across the 12 panels does not correspond to the same absolute change.

ies, providing a measure of confidence in the realism of the results shown below.

\subsection{Transient results}

MPB-caused reductions in $B_{\text {merch }}$ were similar across the three locations and four vegetation coexistence scenarios (Fig. 2). For the Peak regime, the single $100 \%$ mortality event removed all $B_{\text {merch}}$, after which $20-50$ years were needed before NE trees became big enough to have any commercial value. The slower recovery of $B_{\text {merch }}$ in AllPFT compared to other scenarios resulted from the growth release of $\mathrm{BD}$ trees, which were able to grow strongly for a few decades but were very poor long-term competitors at all locations. For the three periodic regimes, the recurring MPB outbreaks prevented $B_{\text {merch }}$ from recovering to the control value as in Peak. We found some evidence of a biophysical interaction between DSTs and regrowing NE trees for the Peak regime in the NEonly, NE-LCcons, and NE-LC scenarios: after the $100 \%$ mortality event, NPP of NE trees increased rapidly but, after about 20-25 years, decreased no- ticeably for $\sim 10$ years before resuming again (similarly to the results shown in Fig. 2 from Landry et al., 2016). We believe this response resulted from the interception of radiation by DSTs, which warmed the upper canopy and initially allowed regrowing NE trees to perform photosynthesis more efficiently at a higher temperature. This warming effect decreased as DSTs fell, causing productivity of the regrowing $\mathrm{NE}$ trees to decline even though they were intercepting more light. In the AllPFT scenario, the slower regrowth of NE trees caused them to miss the warming effect due to the presence of DSTs.

The impacts of MPB on $C_{\text {eco }}$ (Fig. 3) were much more

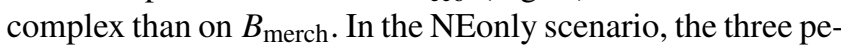
riodic regimes led to gradual declines in $C_{\text {eco }}$ that showed indications of possible stabilization towards the end of the simulations, whereas for the Peak regime, $C_{\text {eco }}$ was still recovering after 240 years. The results were qualitatively the same in the NE-LCcons scenario, albeit with much smaller $\Delta C_{\text {eco }}$ because the lower-canopy growth release partially compensated for the death of NE trees. At the southern location, the 


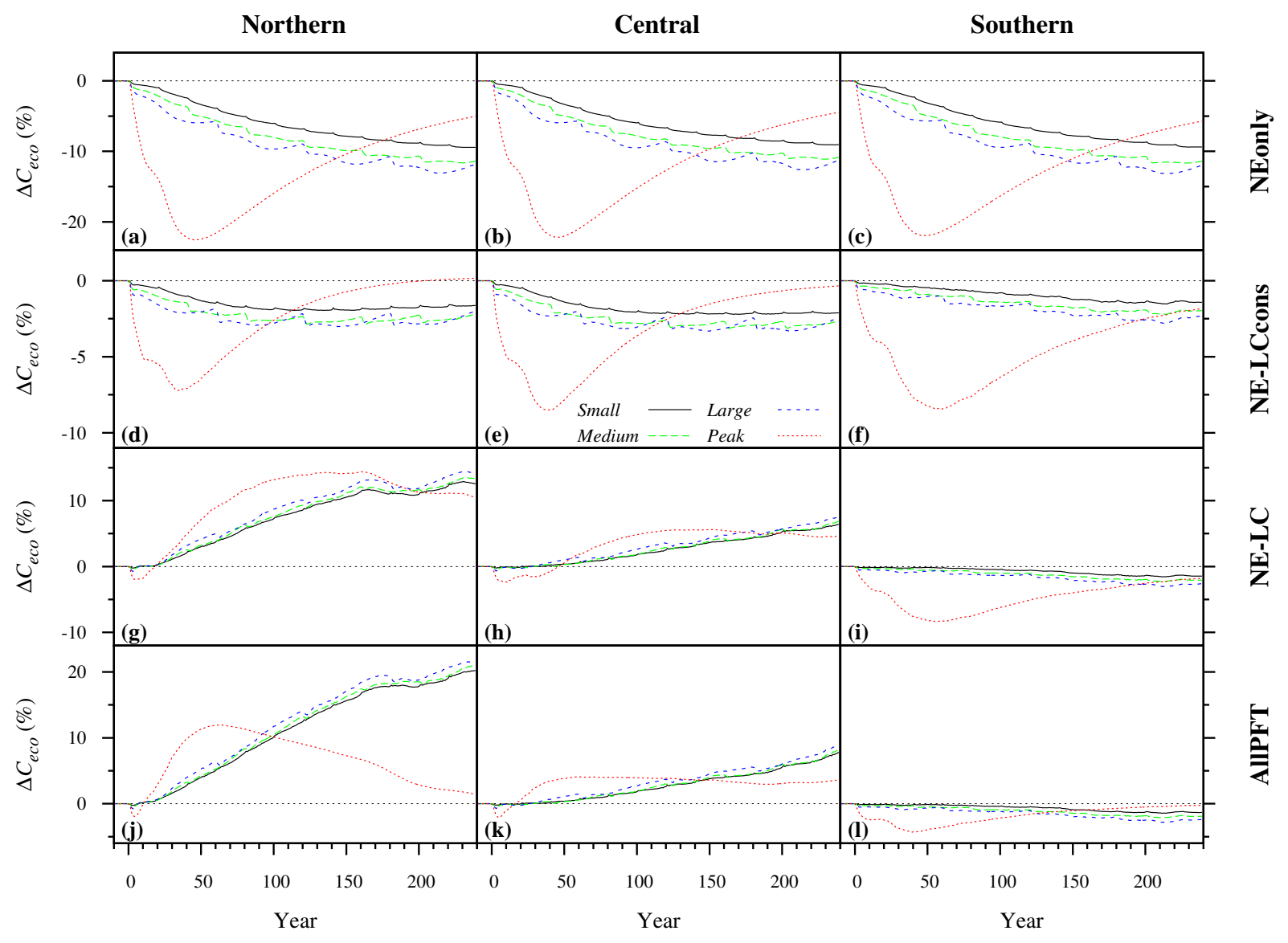

Figure 3. Transient effect of the different MPB outbreak regimes on ecosystem carbon $\left(C_{\text {eco }}\right)$ compared with the no-outbreak control run (first outbreak occurred in year 1). The columns correspond to the three locations (Fig. 1) and the rows to the four vegetation coexistence scenarios (Table 2); the $y$ axis scale differs across the four rows. Control values differed among locations and vegetation coexistence scenarios, so the same relative change (in \%) across the 12 panels does not correspond to the same absolute change.

growing-season soil moisture stress probably explains why the growth release of non-target PFTs was only marginally stronger in the unconstrained NE-LC and AllPFT scenarios vs. NE-LCcons. Conversely, MPB outbreaks substantially increased total NPP at the northern and central locations for NE-LC and AllPFT, by inducing a strong growth release of the non-target vegetation and fostering the increased coexistence of PFTs occupying different ecological niches (upper vs. lower canopies, and evergreen needleleaf vs. deciduous broadleaf strategies) compared to undisturbed forests dominated by lodgepole pine. Here, the higher productivity of the non-target vegetation exceeded the productivity losses and gradual decomposition of killed NE trees; hence, after a delay of a few years to a few decades, $\Delta C_{\text {eco }}$ switched from negative to positive (Fig. 3g, h, j, and k).

MPB outbreaks increased $\alpha$ for all locations and vegetation coexistence scenarios (Fig. 4). Results were very similar across locations and scenarios, except for smaller $\alpha$ increases in AllPFT (panels j, k, and l) for the Peak regime due to the absorption of radiation by BD trees (even when leafless dur- ing winter, as IBIS accounts for the snow-masking effect of stems) following their growth release.

RF varied substantially across locations and vegetation coexistence scenarios (Fig. 5; also see Fig. S1 in the Supplement for the $\mathrm{CO}_{2}$-based and $\alpha$-based components of the total RF for Peak). For NEonly and NE-LCcons, and for the other scenarios at the southern location only, RF was almost always positive, indicating a warming effect of MPB outbreaks on the global climate. The small negative RF values observed for the Peak regime in three instances (panels d, e, and l) came from a combination of still slightly positive $\Delta \alpha$, almost complete return of $C_{\text {eco }}$ to the control values (see Fig. 3), and long time lags in atmosphere-ocean $\mathrm{CO}_{2}$ exchanges following vegetation regrowth (see Landry and Matthews (2016) for such time lags after the simulation of fire disturbances in a coupled climate-carbon model; here, these time lags were accounted for by the convolution approach used to compute $\mathrm{RF}$ as explained in Appendix A). At the northern and central locations, MPB outbreaks under the NE-LC and AllPFT scenarios led instead to a net cooling effect on the global 


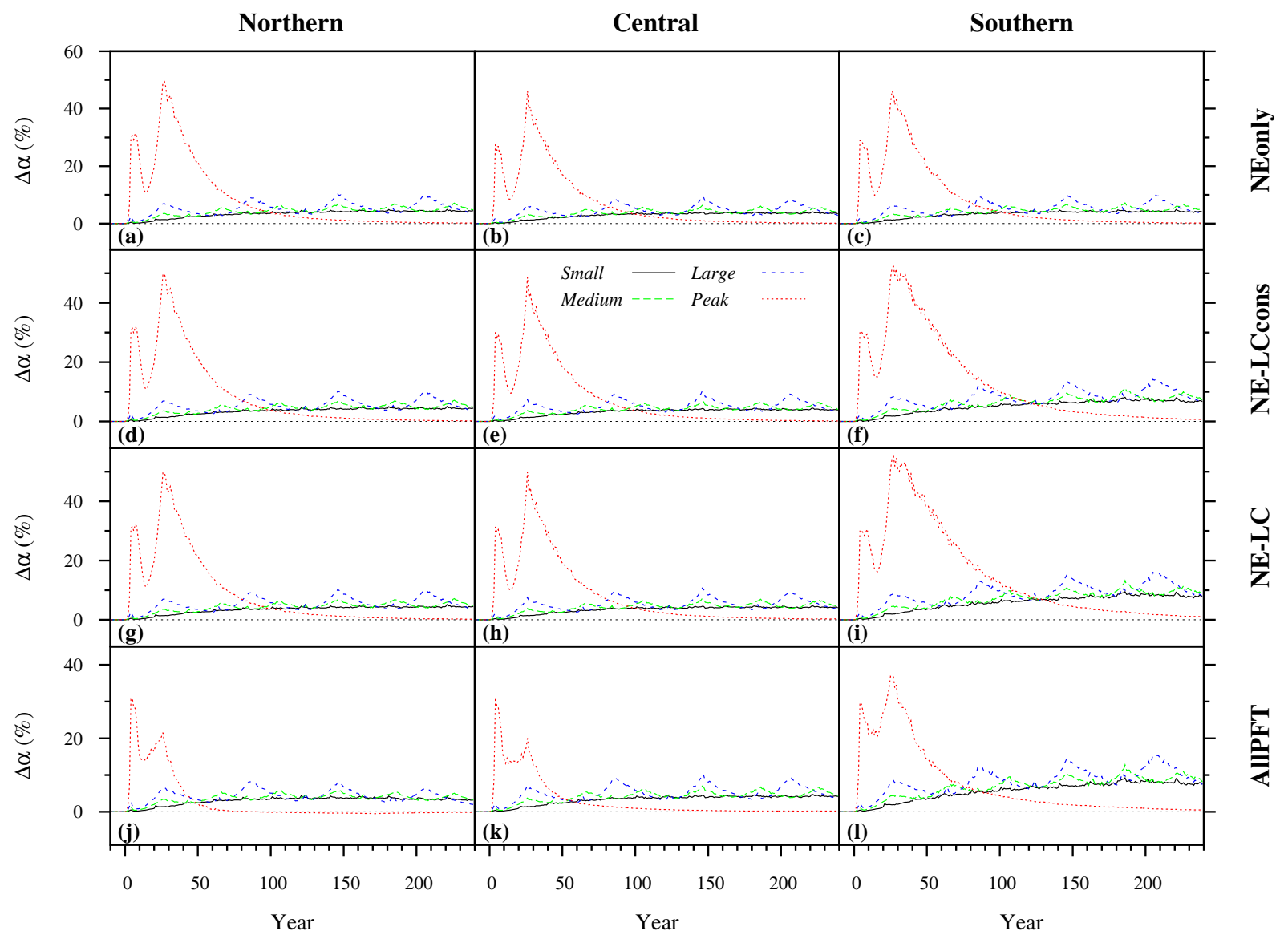

Figure 4. Transient effect of the different MPB outbreak regimes on surface albedo $(\alpha)$ compared with the no-outbreak control run (first outbreak occurred in year 1). The columns correspond to the three locations (Fig. 1) and the rows to the four vegetation coexistence scenarios (Table 2). Control values differed among locations and vegetation coexistence scenarios, so the same relative change (in $\%$ ) across the 12 panels does not correspond to the same absolute change.

climate, even though RF values were initially positive for at least 4 years (panels $\mathrm{g}, \mathrm{h}, \mathrm{j}$, and $\mathrm{k}$ ).

\subsection{Mean effect}

Figure 6 shows the mean time-averaged effect of MPB outbreaks on the four variables over the 240 years following the first outbreak. In the NEonly scenario, the results were almost equal in all three locations for a given MPB regime despite the different climatic conditions. When other PFTs coexisted with the target NE trees, however, the influence of climate became noticeable, especially in the NE-LC and AllPFT scenarios. Figure 6 also reveals that a higher perevent mortality generally caused stronger absolute effects than a shorter return interval. Indeed, for a given location and vegetation coexistence scenario, the departure from zero for the periodic outbreak regimes was generally in the following order: Large $>$ Medium $>$ Small. Moreover, the single $100 \%$ mortality event under the Peak regime had a mean effect comparable to, and in many instances greater than, the mean effect under the three periodic regimes, despite a 240 -year mean mortality of $0.41 \overline{6} \% \mathrm{yr}^{-1}$ for Peak vs. $0.8 \overline{3} \% \mathrm{yr}^{-1}$ for the periodic regimes.

Figure 6 also suggests that RF was more closely linked to $\Delta C_{\text {eco }}$ than to $\Delta \alpha$, which is supported by the transient results where RF basically mirrored $\Delta C_{\text {eco }}$ (compare Figs. 3 and 5; also see Fig. S1). Even though the $\alpha$-caused cooling effect offset a fraction of the $\mathrm{CO}_{2}$-based warming when $\Delta C_{\text {eco }}$ was negative or added to the $\mathrm{CO}_{2}$-based cooling when $\Delta C_{\text {eco }}$ was positive, the sign of RF was primarily related to $C_{\text {eco }}$ changes. Spearman's rank correlation coefficient between $\Delta C_{\text {eco }}$ and RF across the 48 outbreak simulations presented in Fig. 6 was -0.99 , indicating that greater decreases (increases) in $C_{\text {eco }}$ were almost invariably associated with greater increases (decreases) in RF, thereby leading to a greater warming (cooling) effect. On the contrary, Spearman's rank correlation coefficient between $\Delta \alpha$ and RF was only +0.21 , indicating a weak association that was opposite to the actual effect of increased $\alpha$ on RF. 


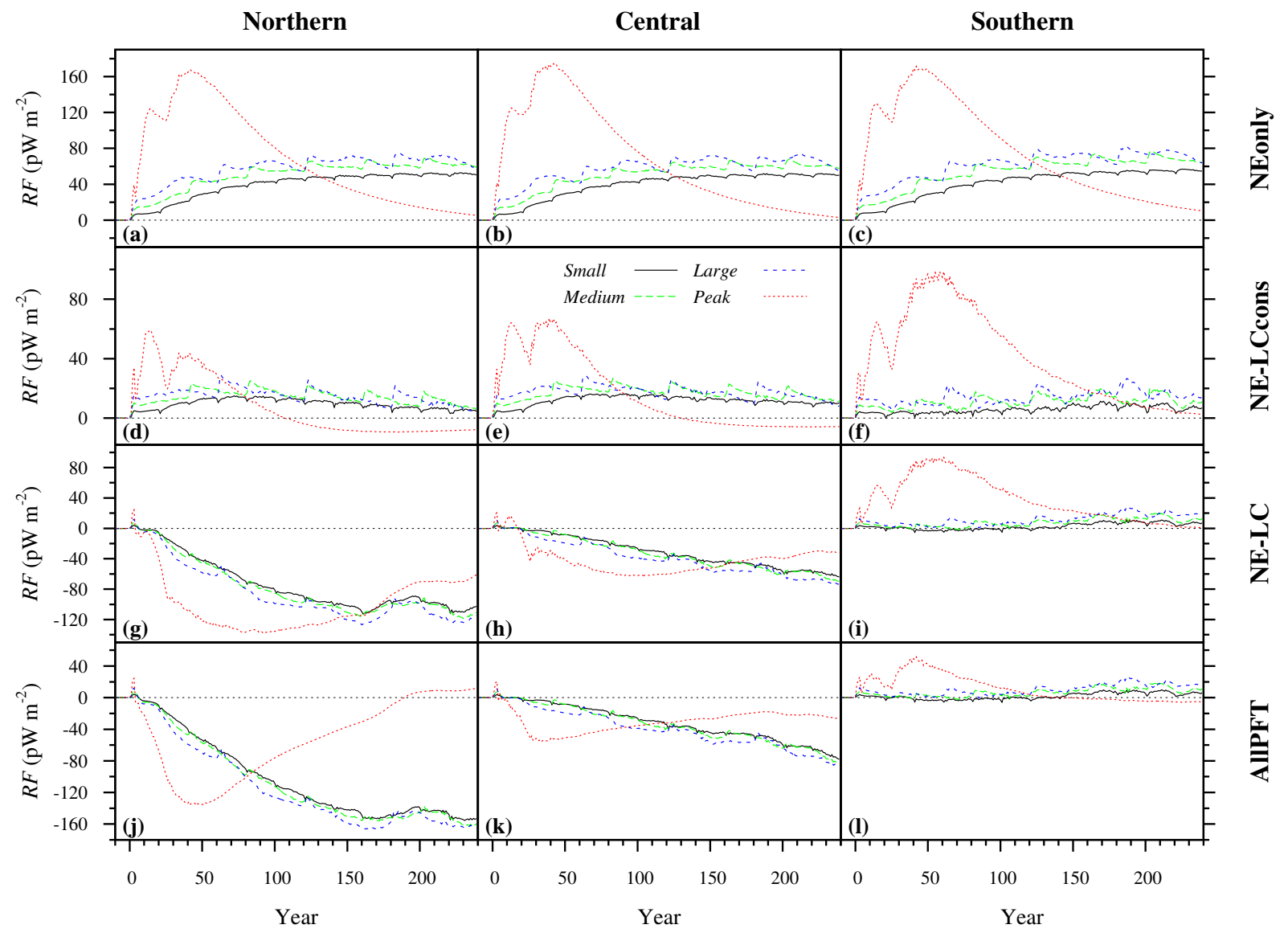

Figure 5. Transient effect of the different MPB outbreak regimes on radiative forcing (RF; in pico-W $\mathrm{m}^{-2}$, for 1 ha outbreaks) compared with the no-outbreak control (first outbreak occurred in year 1). The columns correspond to the three locations (Fig. 1) and the rows to the four vegetation coexistence scenarios (Table 2); the $y$ axis scale differs across the four rows.

\subsection{Comparison of MPB to anthropogenic $\mathrm{CO}_{2}$ emissions}

The highest (positive) yearly RF value came from the NEonly scenario at the central location (Fig. 5b), whereas the lowest (negative) yearly RF value came from the NE-LC scenario at the northern location (Fig. $5 \mathrm{~g}$ ). We therefore recomputed these two RF trajectories over an area of 18.1 Mha to obtain the bounding positive and negative responses, respectively. As shown in Fig. 7, these bounding RF responses invariably had smaller absolute impacts than a single pulse of $+0.83 \mathrm{Pg} \mathrm{C}$ of fossil fuel $\mathrm{CO}_{2}$ for the warming case or a single pulse of $-0.80 \mathrm{PgC}$ (avoided emissions) for the cooling case.

\section{Discussion}

\subsection{Influence of the non-target vegetation}

Our main finding is that the non-target vegetation has a major influence on ecosystem carbon storage and net climatic impact following MPB outbreaks. The substantial variability in $C_{\text {eco }}$ (Fig. 3) and RF (Fig. 5) responses occurred despite almost identical recovery of the MPB-targeted dominant tree species across the four vegetation coexistence scenarios and three locations (Fig. 2). Previous studies not accounting for growth release of the non-target vegetation, including shrubs and grasses, may therefore have overestimated the MPB-caused decreases of $C_{\text {eco }}$. Strong compensatory responses following MPB or other bark beetle outbreaks have also been reported in previous studies that used controls or considered several mortality levels (Heath and Alfaro, 1990; Stone and Wolfe, 1996; Klutsch et al., 2009; Griffin et al., 2011; Amoroso et al., 2013; Hawkins et al., 2013), including cases of NPP or aboveground tree biomass being higher with than without insect outbreaks for some period of time (Romme et al., 1986; Seidl et al., 2008; Pfeifer et al., 2011; Hansen, 2014). Modelling studies on a centennial timescale also found that $C_{\text {eco }}$ can be higher when insect disturbances are simulated than without them (Seidl et al., 2008; Albani et al., 2010), while field-based studies have concluded that the growth release of the surviving vegeta- 


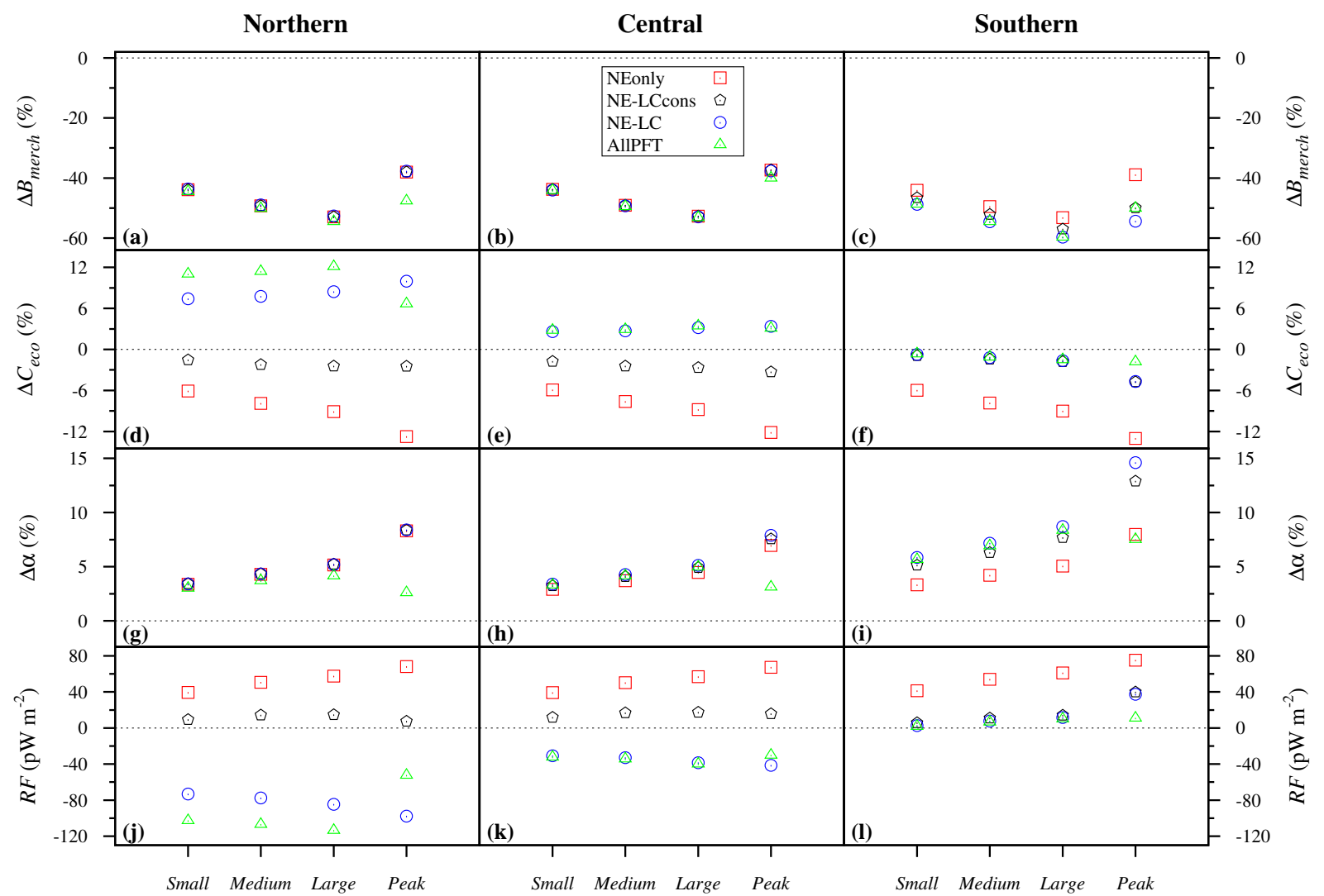

Figure 6. Mean effect over 240 years of the different MPB outbreak regimes on lodgepole pine merchantable biomass $\left(B_{\text {merch }}\right)$, ecosystem carbon $\left(C_{\text {eco }}\right)$, surface albedo $(\alpha)$, and radiative forcing (RF; in pico-W m ${ }^{-2}$, for 1 ha outbreaks) compared with the no-outbreak control, for the three locations (Fig. 1) and four vegetation coexistence scenarios (Table 2). Control values differed among locations and vegetation coexistence scenarios, so the same relative change (in \%; panels a through i) does not correspond to the same absolute change.

tion can contribute to a fast recovery of NEP following MPB outbreaks (Bowler et al., 2012; Brown et al., 2012) and even to stable growing-season NEP despite ongoing increases in MPB mortality (Reed et al., 2014). Another field-based study found $C_{\text {eco }}$ to be almost equal in control stands and stands affected $25-30$ years earlier by a $\sim 25 \%$-mortality MPB outbreak (Kashian et al., 2013).

We do not believe that one of the vegetation coexistence scenarios we simulated is fundamentally more realistic than the others. Rather, we believe that these four scenarios sample the ensemble of possible responses to MPB outbreaks, because the amount and composition of non-target vegetation vary substantially among MPB-attacked stands, even over short distances, which leads to variable regeneration pathways (Axelson et al., 2009; Amoroso et al., 2013; Hawkins et al., 2013; Pelz and Smith, 2013; Alfaro et al., 2015; Campbell and Antos, 2015). Given this substantial variability, trying to bracket the range of possible vegetation responses, like we did here, appears safer for large-scale modelling studies than aiming to forecast one specific course of events. Contrary to our simulation protocol, however, it is unlikely that the composition of non-target vegetation would remain unchanged from one outbreak to the next. Moreover, most forests in western North America undergo recurrent standclearing fires or wood harvests, resetting stands on trajectories that, according to the evidence currently available, are not strongly affected by the previous occurrence of MPB outbreaks (Hicke et al., 2012b; Harvey et al., 2014).

\subsection{Climatic impact}

The only previous study estimating the net impact of MPB outbreaks on global climate found a negative RF throughout the 14-year period studied due to an $\alpha$-based cooling that was invariably stronger than the $C_{\text {eco-based warming }}$ (O'Halloran et al., 2012). This outcome is at odds with IBISMIM results, because our net RF depended critically upon the sign of the $C_{\text {eco }}$ change and, even for instances of overall net cooling, our RF values were positive during the first four years at least (see transient results in panels $g, h, j$, and $\mathrm{k}$ of Fig. S1 for instances of $\alpha$-based cooling being temporarily stronger than $C_{\mathrm{eco}}$-based warming under Peak). This discrepancy likely involves methodological differences between the two studies but might also come from a spa- 
tiotemporal mismatch that could have affected the RF results from O'Halloran et al. (2012): their $\Delta \alpha$ was representative of MPB-killed stands (coming from time-since-mortality comparisons at the stand level), whereas their $\Delta C_{\text {eco }}$ was based on the regional-level results of Kurz et al. (2008), which were for stands killed at different times averaged with unaffected stands.

Our estimate of the global climatic impact due to the MPB outbreak in British Columbia (Fig. 7), although very simple, seems appropriate to bound the range of possible values. For the warming case, the maximum decrease in $C_{\text {eco }}$ (based on Peak from Fig. 3b, over 18.1 Mha) was equal to $818 \mathrm{Tg} \mathrm{C} \sim 50$ years after mortality; for this same case, the decrease 21 years after mortality was $490 \mathrm{Tg}$ C. By comparison, Kurz et al. (2008) simulated a 2000-2020 decrease of $270 \mathrm{Tg} C$ with an inventory-based model omitting the possible growth release of the non-target vegetation and projections of MPB-caused mortality almost $40 \%$ higher than more recent estimates (Walton, 2013), whereas Arora et al. (2016) simulated a 1999-2050 decrease of $580 \mathrm{Tg} C$ with a vegetation coexistence scenario similar to NEonly in an IBIS-like model. For the cooling case, the lower-canopy growth release in the unconstrained NE-LC scenario was likely too strong, causing the increase in $C_{\text {eco }}$ to be overestimated. Consequently, the actual impact probably lies within these bounding responses, which have smaller absolute $\mathrm{RF}$ than a single pulse of $+0.83 \mathrm{PgC}$ (warming case) or $-0.80 \mathrm{PgC}$ (cooling case) of fossil fuel $\mathrm{CO}_{2}$. Pulses of such magnitude represent approximately 1 month of current global $\mathrm{CO}_{2}$ emissions from fossil fuel combustion and cement production (Le Quéré et al., 2015). Even though these results suggest a marginal impact on global temperature, the current MPB outbreak in British Columbia could add or offset a sizable share of the warming due to greenhouse gas (GHG) emissions from the province alone or Canada as a whole. Total GHG emissions were estimated at $61.5 \mathrm{MtCO}_{2}$ eq in British Columbia for 2012 (British Columbia, 2012a) and at $726 \mathrm{MtCO}_{2} \mathrm{eq}$ in Canada for 2013 (Environment Canada, 2014), which are roughly equivalent to 0.017 and $0.20 \mathrm{Pg} \mathrm{C}$ of fossil fuel $\mathrm{CO}_{2}$, respectively. Therefore, the upper bound on the maximum global climatic impact of the current MPB outbreak in British Columbia, for either warming $(+0.83 \mathrm{PgC})$ or cooling $(-0.80 \mathrm{Pg} \mathrm{C})$, is equivalent to $\mathrm{GHG}$ emissions over roughly 50 years for British Columbia and 4 years for Canada. A more adequate assessment would require a dedicated study going beyond the simplified analysis presented here, which could only provide an upper bound for either a net warming or net cooling effect.

It is important to remember that the RF concept does not apply to changes in local temperature. Since the $\alpha$-based cooling is local whereas the $\mathrm{CO}_{2}$-based effect is global, one could expect that MPB outbreaks always decrease local temperature. However, this perspective neglects the post-MPB changes in sensible and latent heat fluxes that also modulate local temperature. In summer, high levels of MPB mortal-

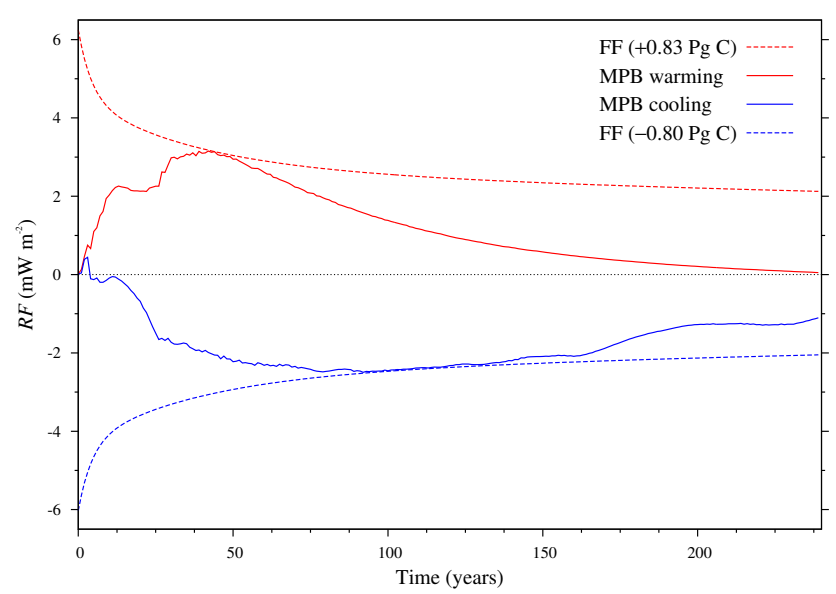

Figure 7. Comparison of the strongest warming and cooling radiative forcing (RF) responses from the MPB Peak outbreaks with the RF from a pulse of fossil fuel (FF) $\mathrm{CO}_{2}$ emissions (in milli$\mathrm{W} \mathrm{m}^{-2}$ ). The MPB RF were computed for an outbreak area of 18.1 Mha; the warming response came from the NEonly scenario at the central location and the cooling response from the NE-LC scenario at the northern location.

ity have been found to increase surface temperature by up to a few ${ }^{\circ} \mathrm{C}$ due to reduced evapotranspiration (Griffin et al., 2011; Bright et al., 2013; Maness et al., 2013), a response Landry et al. (2016) obtained in their detailed assessment of IBIS-MIM. Landry et al. (2016) also found that MPB outbreaks decreased surface temperature in winter, but they could not find any empirical observations on this variable.

\subsection{Management and research implications}

Management activities aiming to prevent or respond to MPB outbreaks must consider several factors, including economic impacts (e.g., Patriquin et al., 2005) and potential effects on fire behaviour (see the review from Hicke et al., 2012b). Although we did not account for these factors or model management activities explicitly, our study suggests the following. First, our results are in line with an emerging body of empirical literature pointing towards the resilience of carbon storage in MPB-affected forests due to the growth release of the surviving vegetation (Bowler et al., 2012; Brown et al., 2012; Reed et al., 2014). Similar to previous studies (Stone and Wolfe, 1996; Klutsch et al., 2009; Griffin et al., 2011; Bowler et al., 2012; Vanderhoof et al., 2014), we found a growth release of shrubs and grasses - and not only trees - that could contribute to ecosystem-level resilience in carbon storage. This benefit could be compromised if non-target vegetation is damaged during salvage logging operations, which might therefore be detrimental to carbon stewardship. We found indications of the potential growth release of surviving target trees in (1) the fast NPP recovery of NE trees for the three periodic regimes and (2) the comparable $B_{\text {merch }}$ mean decrease for the three periodic regimes vs. Peak despite 
higher average mortality rates (Fig. 6). These outcomes are consistent with the relative stability of aboveground wood NPP for mortality levels below $\sim 60 \%$ in a forest-level manipulation experiment (Stuart-Haëntjens et al., 2015).

Second, our Peak results indicate that high amounts of DSTs could facilitate the growth of the surviving trees by warming the surrounding air. Salvage logging would therefore prevent this beneficial impact (in cool growing seasons) and dampen the growth release of surviving trees. The warming effect of DSTs appears coherent with empirical evidence on vegetation-temperature interactions in northern latitudes (Liu et al., 2006; Lee et al., 2011) but is likely smaller than simulated here due to the overestimation by IBIS of heat storage within tree stems. The impact of DSTs on the amount and partitioning (i.e., direct vs. diffuse) of solar radiation absorbed by the surviving vegetation, which all modulate NPP, is also probably more complex than simulated by IBISMIM. Field studies comparing the vertical profiles of temperature, total solar radiation, and diffuse solar radiation of stands with and without DSTs would be useful to resolve such questions.

Third, since MPB outbreaks do not necessarily warm the global climate, outbreak-preventing activities like preemptive logging might not mitigate climate change. Assessing the net climatic impact of salvage logging is even more complicated, because the exercise needs to go beyond comparing $\mathrm{RF}$ for salvaged and unsalvaged stands and account for the landscape-level redistribution of harvesting activities as well as the differences in the production and fate of the salvagedderived wood products compared to the no-salvage baseline (Lemprière et al., 2013; Landry and Ramankutty, 2015).

Fourth, IBIS-MIM transient results suggest that MPB impacts vary substantially not only across space but also through time. While the spatial variability of vegetation responses (Griesbauer and Green, 2006; Axelson et al., 2009; Amoroso et al., 2013; Hawkins et al., 2013; Pelz and Smith, 2013; Alfaro et al., 2015; Campbell and Antos, 2015) underlines the need for studies in many stands, the temporal variability reported here calls for continued or periodic data gathering over decades at the same sites. A better appreciation of the long-term effects of MPB outbreaks should foster adequate management responses in affected forests within the insect's native range as well as in the Canadian boreal forest where the MPB has already established and may spread as the regional climate warms (Cullingham et al., 2011; Nealis and Cooke, 2014).

\subsection{Study limitations}

Eddy covariance measurements of ecosystem-level carbon exchanges following MPB outbreaks (Bowler et al., 2012; Brown et al., 2012; Reed et al., 2014) extend for less than a decade and lack formal controls, hence limiting our capacity to validate long-term IBIS-MIM output. Many dendrochronological studies have gathered data over longer time periods, sometimes with formal controls, but the results do not translate directly into changes in stand-level NPP. Romme et al. (1986) estimated the effect of MPB on aboveground tree growth, but only for six stands 10-20 years after an outbreak. A single study by Kashian et al. (2013) quantified the impacts of MPB on $C_{\mathrm{eco}}$, through allometric equations and soil samples obtained at 12 stands 25-30 years after mortality; however, this study dealt primarily with fire and the MPB results were qualified as "preliminary" by the authors. Other empirical and modelling studies accounting for possible growth releases support the plausibility of IBIS-MIM responses when simulating additional PFTs besides NE trees, yet our results must be considered tentative because process-based modelling of vegetation competition (Kucharik et al., 2006; Moorcroft, 2006; Purves and Pacala, 2008) and non-stand-replacing disturbances (BondLamberty et al., 2015) remains challenging.

We could not capture the effect of nitrogen availability on post-MPB vegetation recovery (Edburg et al., 2011) because IBIS does not simulate nutrient cycling. Another limitation of IBIS is the representation of a single NE tree PFT and a single BD tree PFT, whereas tree species other than lodgepole pine and trembling aspen often coexist in MPBattacked forests (Griesbauer and Green, 2006; Axelson et al., 2009; Amoroso et al., 2013; Hawkins et al., 2013; Campbell and Antos, 2015). Accounting for these other species could increase the range of post-MPB responses for $C_{\mathrm{eco}}$ and RF and also partly offset the $B_{\text {merch }}$ reductions simulated here, which included lodgepole pine only. Since IBIS does not represent different age cohorts within the same PFT, we could not formally assess the growth release of individual surviving NE trees. The post-MPB response of younger trees would likely differ from those of mature trees and MPB impacts on tree demographics could further complicate standlevel responses following an outbreak, for example by increasing total biomass despite reduced productivity because of a strong decrease in competition-related mortality (Pfeifer et al., 2011). IBIS parameters for the different PFTs were also not specifically based on data gathered from British Columbian forests.

Finally, the overestimated heat storage in tree stems could underestimate the MPB-caused $\alpha$ increase, thereby biasing RF towards a warming effect. Conversely, another potential bias could overestimate the cooling effect of $\alpha$ increase: while a seminal study concluded that $\alpha$ and atmospheric $\mathrm{CO}_{2}$ act with the same "efficacy" on the global surface temperature (Hansen et al., 2005), other studies have found that $\alpha$ has a lower efficacy than $\mathrm{CO}_{2}$ (Hansen et al., 1997; Davin et al., 2007). MPB outbreaks can also affect the global climate through other mechanisms that are poorly constrained and that we did not consider, for example changes in atmospheric chemistry (Arneth and Niinemets, 2010) or in the partitioning between latent and sensible heat fluxes (BanWeiss et al., 2011). 


\section{Conclusions}

Despite major progress over the last decades, various knowledge gaps still limit the understanding of the consequences of MPB outbreaks. In this study, we used a climate-driven process-based ecosystem model to estimate the long-term impacts of prescribed MPB outbreaks. We found that the differences in vegetation coexistence scenario and location had little influence over MPB impacts on lodgepole pine merchantable biomass ( $B_{\text {merch }}$; Fig. 2$)$ and surface albedo $(\alpha$; Fig. 4). On the contrary, accounting for the non-target vegetation invariably reduced losses of ecosystem carbon $\left(C_{\mathrm{eco}}\right)$ and, at the two locations not subjected to growing-season soil moisture stress, even led to post-outbreak $C_{\text {eco }}$ increases for the two vegetation coexistence scenarios with the strongest growth release (Fig. 3). Although MPB-induced increases in $\alpha$ always had a cooling influence, the net global warming or cooling effect of MPB outbreaks was determined by the stronger carbon-based responses (see Fig. 6, and compare Fig. 5 with Fig. 3). A simple analysis suggested that the MPB outbreak in British Columbia will have less influence on global temperature over the coming centuries than 1 month of global anthropogenic $\mathrm{CO}_{2}$ emissions at the 2014 level (Fig. 7).

The management and research implications of our study are fourfold. First, salvage logging, particularly when performed as clear-cut harvesting, may be detrimental to carbon stewardship when surviving trees and other lower-canopy vegetation are abundant. Second, salvage logging could slow forest recovery if, following high MPB mortality, tree productivity is indeed increased due to the physical presence of dead standing trees, a hypothesis that should be subject to empirical studies. Third, MPB disturbances might not necessarily lead to global warming, so activities aiming to prevent or control outbreaks (e.g., preemptive logging) should not be heralded as climate mitigation strategies without more detailed analyses. Fourth, the substantial spatiotemporal variability in MPB-induced changes suggests a need to support field studies that encompass a wide range of stand conditions and are maintained over several decades.

\section{Code availability}

IBIS-MIM code is available upon request from the corresponding author or through the following link: http://landuse.geog.mcgill.ca/ jean-sebastien.landry2@ mail.mcgill.ca/ibismim/.

\section{Data availability}

Simulation results (as NetCDF files; http://www.unidata. ucar.edu/software/netcdf/) are available upon request from the corresponding author. 


\section{Appendix A: Additional computations}

\section{A1 Merchantable biomass}

$B_{\text {merch }}$ is a fraction of the total tree biomass in a forest, because immature trees, as well as tops, branches, and stumps from mature trees, are excluded. We computed $B_{\text {merch }}$ as the product of prop, which is the proportion (unitless) of the total tree biomass that is merchantable, and $B_{\text {tot }}$, which is the total tree biomass (in $\mathrm{kg} \mathrm{C} \mathrm{m}^{-2}$ ) estimated by IBIS. We derived prop from Fig. 5 of Kurz et al. (2009), which shows $B_{\text {merch }}$ and $B_{\text {tot }}$ as a function of time for a lodgepole pine stand:

prop $=\left\{\begin{array}{l}0 \text { if } B_{\mathrm{tot}} / B_{\max }<0.21 \\ 0.5058+0.3172 \times \ln \left(B_{\mathrm{tot}} / B_{\mathrm{max}}\right) \text { otherwise, }\end{array}\right.$

where $B_{\max }$ is the maximum tree biomass (in $\mathrm{kg} \mathrm{C} \mathrm{m}^{-2}$ ) at equilibrium. The logarithmic function for prop provided a good fit $\left(R^{2}=0.996\right)$ with the data extracted from Kurz et al. (2009).

\section{A2 Radiative forcing}

\section{A2.1 Mountain pine beetle}

The net RF was the sum of the radiative forcing from atmospheric $\mathrm{CO}_{2}$ changes $\left(\mathrm{RF}_{\mathrm{CO}_{2}}\right)$ and from $\alpha$ changes $\left(\mathrm{RF}_{\mathrm{alb}}\right)$. $\mathrm{RF}_{\mathrm{CO}_{2}}$ in year $y$ caused by a change in atmospheric $\mathrm{CO}_{2}$ in the same year $(\Delta C(y)$, in ppmv) compared to a reference concentration $\left(C_{o}\right.$, in ppmv) was given by (Myhre et al., 1998)

$\mathrm{RF}_{\mathrm{CO}_{2}}(y)=5.35 \times \ln \left(1+\frac{\Delta C(y)}{C_{o}}\right)$.

The change in atmospheric $\mathrm{CO}_{2}$ in year $y$ due to MPB outbreaks resulted from all past changes in $C_{\text {eco }}$ computed by IBIS-MIM, including vegetation regrowth, while accounting for the airborne fraction of these past fluxes. In other words, $\Delta C(y)$ was the convolution of the series of past yearly land-to-atmosphere fluxes with the impulse response function (IRF) for the airborne fraction of these past fluxes. Since $\Delta C(y)$ is an absolute amount and not a change per unit of land area disturbed, we must compute it for a specific area $A_{\mathrm{MPB}}\left(\right.$ in $\mathrm{m}^{2}$ ) of MPB mortality. We thus computed $\Delta C(y)$ as

$\Delta C(y)=A_{\mathrm{MPB}} \times k \times \sum_{t=0}^{y-1} \delta C_{\mathrm{eco}}(y-t) \times \operatorname{IRF}(t)$,

where $k$ is equal to $4.69 \times 10^{-13}$ ppmv per $\mathrm{kgC}$ (CDIAC, $2012)$ and $\delta C_{\text {eco }}(x)=\left(C_{\text {eco,control }}(x)-C_{\text {eco,control }}(x-1)\right)-$
$\left(C_{\text {eco,MPB }}(x)-C_{\text {eco,MPB }}(x-1)\right)$. For the $\operatorname{IRF}(t)$ function (unitless), we used the mean response from the injection of a single pulse of $\mathrm{CO}_{2}$ into 15 different coupled climatecarbon models (Joos et al., 2013). A similar approach has already been used to estimate $\mathrm{RF}_{\mathrm{CO}_{2}}$ from MPB outbreaks (O'Halloran et al., 2012).

We estimated the radiative forcing in year $y$ caused by a change in $\alpha$ as the mean of monthly values:

$$
\operatorname{RF}_{\mathrm{alb}}(y)=\frac{1}{365} \times \sum_{m=1}^{12} n_{\text {days }}(m) \times \mathrm{RF}_{\mathrm{alb}}(m, y),
$$

where $n_{\text {days }}(m)$ is the number of days in month $m$, and $\operatorname{RF}_{\text {alb }}(m, y)$ is the average $\alpha$-caused radiative forcing in month $m$ of year $y$. To estimate $\operatorname{RF}_{\text {alb }}(m, y)$, we used the radiative kernels approach (Shell et al., 2008; Soden et al., 2008), which gives the radiative forcing caused by a unit change in a component of the climate system and has already been employed in previous studies on MPB-induced changes in $\mathrm{RF}_{\mathrm{alb}}$ (O'Halloran et al., 2012; Vanderhoof et al., 2014). Using the $\alpha$ radiative kernel for month $m\left(K_{\mathrm{alb}}(m)\right.$, in $\mathrm{W} \mathrm{m}^{-2}$ ), we could thus estimate the $\alpha$-caused radiative forcing as (Shell et al., 2008; Soden et al., 2008)

$\operatorname{RF}_{\mathrm{alb}}(m, y)=\frac{A_{\mathrm{MPB}}}{A_{\mathrm{Earth}}} \times K_{\mathrm{alb}}(m) \times \Delta \alpha(m, y)$,

where $A_{\text {Earth }}$ is the Earth area $\left(5.1 \times 10^{14} \mathrm{~m}^{2}\right.$; Wallace and Hobbs (2006)) and $\Delta \alpha(m, y)$ is the change in $\alpha$ between a simulation with MPB mortality and the control simulation. We averaged $K_{\mathrm{alb}}(m)$ from two models: the Community Atmospheric Model (data downloaded from http://people. oregonstate.edu/ shellk/kernel.html) and the Geophysical Fluid Dynamics Laboratory atmospheric model (data downloaded from http://www.rsmas.miami.edu/personal/bsoden/ data/kernels.html).

We computed the net RF for an outbreak area of 1 ha (i.e., $A_{\mathrm{MPB}}=10000 \mathrm{~m}^{2}$ ). Strictly speaking, the RF results we obtained cannot be directly scaled as a function of the disturbed area, because Eq. (A2) is not linear and the $K_{\mathrm{alb}}(m)$ values in Eq. (A5) vary spatially. However, both these restrictions can be ignored for regional-level scaling of our RF results. First, the changes in total atmospheric $\mathrm{CO}_{2}$ were very small, so that Eq. (A2) varied almost linearly with $\Delta C(y)$ as $\ln (1+x) \approx x$ for very small values of $x$. Second, $K_{\mathrm{alb}}(m)$ values were computed at a coarse resolution of $\geq 2^{\circ}$ and are spatially correlated. Therefore, RF for a MPB-disturbed area of $10000 \mathrm{ha}$, for example, would be very well approximated by multiplying our reported results by a factor of 10000 . 


\section{A2.2 Fossil fuel $\mathrm{CO}_{2}$}

The radiative forcing caused by a positive or negative pulse of fossil fuel $\mathrm{CO}_{2}$ emissions was also computed based on Eq. (A2), with $\Delta C(y)$ being given by

$\Delta C(y)=k \times P \times \operatorname{IRF}(y-1)$,

where $P$ is the value of the single pulse of emissions (in $\mathrm{kg} \mathrm{C}$ ) occurring in year 1, with $k$ and IRF as in Eq. (A3). We varied $P$ until obtaining a radiative forcing response that was invariably greater (smaller) than the bounding MPB-caused positive (negative) RF response throughout the 240 years. 


\section{The Supplement related to this article is available online at doi:10.5194/bg-13-5277-2016-supplement.}

Author contributions. Jean-Sébastien Landry designed the study with advice from Lael Parrott, David T. Price, and Navin Ramankutty; Jean-Sébastien Landry performed the simulations with IBIS-MIM and analyzed the results; Jean-Sébastien Landry prepared the paper with contributions from all co-authors.

Acknowledgements. We thank Dany Plouffe for producing Fig. 1 and the Concordia Climate Lab for feedback on the results. The comments from three reviewers helped us improve the manuscript. Jean-Sébastien Landry was funded by a doctoral scholarship (B2) from the Fonds de recherche du Québec - Nature et technologies (FRQNT).

Edited by: A. Rammig

Reviewed by: three anonymous referees

\section{References}

Albani, M., Moorcroft, P. M., Ellison, A. M., Orwig, D. A., and Foster, D. R.: Predicting the impact of hemlock woolly adelgid on carbon dynamics of eastern United States forests, Can. J. Forest Res., 40, 119-133, 2010.

Alfaro, R. I., van Akker, L., and Hawkes, B.: Characteristics of forest legacies following two mountain pine beetle outbreaks in British Columbia, Canada, Can. J. Forest Res., 45, 1387-1396, 2015.

Amoroso, M. M., Coates, K. D., and Astrup, R.: Stand recovery and self-organization following large-scale mountain pine beetle induced canopy mortality in northern forests, Forest Ecol. Manag., 310, 300-311, 2013.

Arneth, A. and Niinemets, U.: Induced BVOCs: how to bug our models?, Trends Plant Sci., 15, 118-125, 2010.

Arora, V. K., Peng, Y., Kurz, W. A., Fyfe, J. C., Hawkins, B., and Werner, A. T.: Potential near-future carbon uptake overcomes losses from a large insect outbreak in British Columbia, Canada, Geophys. Res. Lett., 43, 2590-2598, 2016.

Axelson, J. N., Alfaro, R. I., and Hawkes, B. C.: Influence of fire and mountain pine beetle on the dynamics of lodgepole pine stands in British Columbia, Canada, Forest Ecol. Manag., 257, 18741882, 2009.

Ban-Weiss, G. A., Bala, G., Cao, L., Pongratz, J., and Caldeira, K.: Climate forcing and response to idealized changes in surface latent and sensible heat, Environ. Res. Lett., 6, 034-032, 2011.

Bond-Lamberty, B., Fisk, J. P., Holm, J. A., Bailey, V., Bohrer, G., and Gough, C. M.: Moderate forest disturbance as a stringent test for gap and big-leaf models, Biogeosciences, 12, 513-526, doi:10.5194/bg-12-513-2015, 2015.

Bowler, R., Fredeen, A. L., Brown, M., and Black, T. A.: Residual vegetation importance to net $\mathrm{CO}_{2}$ uptake in pinedominated stands following mountain pine beetle attack in British Columbia, Canada, Forest Ecol. Manag., 269, 82-91, 2012.
Bright, B. C., Hicke, J. A., and Meddens, A. J. H.: Effects of bark beetle-caused tree mortality on biogeochemical and biogeophysical MODIS products, J. Geophys. Res.-Biogeo., 118, 974-982, 2013.

British Columbia: Greenhouse Gas Inventory Report, Ministry of Environment, 77 pp., 2012a.

British Columbia: Facts About B.C.'s Mountain Pine Beetle - Updated May 2012, available at: http://www.for.gov.bc.ca/ hfp/mountain_pine_beetle/facts.htm (last access: 21 November 2014), 2012b.

Brown, M. G., Black, T. A., Nesic, Z., Fredeen, A. L., Foord, V. N., Spittlehouse, D. L., Bowler, R., Burton, P. J., Trofymow, J. A., Grant, N. J., and Lessard, D.: The carbon balance of two lodgepole pine stands recovering from mountain pine beetle attack in British Columbia, Agr. Forest Meteorol., 153, 82-93, 2012.

Brunelle, A., Rehfeldt, G. E., Bentz, B., and Munson, A. S.: Holocene records of Dendroctonus bark beetles in high elevation pine forests of Idaho and Montana, USA, Forest Ecol. Manag., 255, 836-846, 2008.

Campbell, E. M. and Antos, J. A.: Advance regeneration and trajectories of stand development following the mountain pine beetle outbreak in boreal forests of British Columbia, Can. J. Forest Res., 45, 1327-1337, 2015.

CDIAC: Carbon Dioxide Information Analysis Center - Conversion Tables, available at: http://cdiac.ornl.gov/pns/convert.html, last access: 13 August 2012.

Cullingham, C. I., Cooke, J. E. K., Dang, S., Davis, C. S., Cooke, B. J., and Coltman, D. W.: Mountain pine beetle host-range expansion threatens the boreal forest, Mol. Ecol., 20, 2157-2171, 2011.

Davin, E. L., de Noblet-Ducoudré, N., and Friedlingstein, P.: Impact of land cover change on surface climate: Relevance of the radiative forcing concept, Geophys. Res. Lett., 34, L13702, doi:10.1029/2007GL029678, 2007.

Delire, C. and Foley, J. A.: Evaluating the performance of a land surface ecosystem model with biophysical measurements from contrasting environments, J. Geophys. Res., 104, 16895-16909, 1999.

Dietze, M. C. and Matthes, J. H.: A general ecophysiological framework for modelling the impact of pests and pathogens on forest ecosystems, Ecol. Lett., 17, 1418-1426, 2014.

Edburg, S. L., Hicke, J. A., Lawrence, D. M., and Thornton, P. E.: Simulating coupled carbon and nitrogen dynamics following mountain pine beetle outbreaks in the western United States, J. Geophys. Res., 116, G04033, doi:10.1029/2011JG001786, 2011.

El Maayar, M., Price, D. T., Delire, C., Foley, J. A., Black, T. A., and Bessemoulin, P.: Validation of the Integrated Biosphere Simulator over Canadian deciduous and coniferous boreal forest stands, J. Geophys. Res., 106, 14339-14355, 2001.

El Maayar, M., Price, D. T., Black, T. A., Humphreys, E. R., and Jork, E.-M.: Sensitivity Tests of the Integrated Biosphere Simulator to Soil and Vegetation Characteristics in a Pacific Coastal Coniferous Forest, Atmos.-Ocean, 40, 313-332, 2002.

Environment Canada: National Inventory Report 1990-2013: Greenhouse Gas Sources and Sinks in Canada - Executive Summary, 11 pp., 2014.

Foley, J. A., Prentice, I. C., Ramankutty, N., Levis, S., Pollard, D., Sitch, S., and Haxeltine, A.: An integrated biosphere model of 
land surface processes, terrestrial carbon balance, and vegetation dynamics, Global Biogeochem. Cy., 10, 603-628, 1996.

Ghimire, B., Williams, C. A., Collatz, G. J., Vanderhoof, M., Rogan, J., Kulakowski, D., and Masek, J. G.: Large carbon release legacy from bark beetle outbreaks across Western United States, Glob. Change Biol., 21, 3087-3101, 2015.

Griesbauer, H. and Green, S.: Examining the utility of advance regeneration for reforestation and timber production in unsalvaged stands killed by the mountain pine beetle: Controlling factors and management implications, BC J. Ecosys. Manag., 7, 81-92, 2006.

Griffin, J. M., Turner, M. G., and Simard, M.: Nitrogen cycling following mountain pine beetle disturbance in lodgepole pine forests of Greater Yellowstone, Forest Ecol. Manag., 261, 10771089, 2011.

Hansen, E. M.: Forest Development and Carbon Dynamics after Mountain Pine Beetle Outbreaks, Forest Sci., 60, 476-488, 2014.

Hansen, J., Sato, M., and Ruedy, R.: Radiative forcing and climate response, J. Geophys. Res., 102, 6831-6864, 1997.

Hansen, J., Sato, M., Ruedy, R., Nazarenko, L., Lacis, A., Schmidt, G. A., Russell, G., Aleinov, I., Bauer, M., Bauer, S., Bell, N., Cairns, B., Canuto, V., Chandler, M., Cheng, Y., Del Genio, A., Faluvegi, G., Fleming, E., Friend, A., Hall, T., Jackman, C., Kelley, M., Kiang, N., Koch, D., Lean, J., Lerner, J., Lo, K., Menon, S., Miller, R., Minnis, P., Novakov, T., Oinas, V., Perlwitz, J., Perlwitz, J., Rind, D., Romanou, A., Shindell, D., Stone, P., Sun, S., Tausnev, N., Thresher, D., Wielicki, B., Wong, T., Yao, M., and Zhang, S.: Efficacy of climate forcings, J. Geophys. Res., 110, D18104, doi:10.1029/2005JD005776, 2005.

Harvey, B. J., Donato, D. C., and Turner, M. G.: Recent mountain pine beetle outbreaks, wildfire severity, and postfire tree regeneration in the US Northern Rockies, P. Natl. Acad. Sci. USA, 111, 15120-15125, 2014.

Hawkins, C. D. B., Dhar, A., and Balliet, N. A.: Radial growth of residual overstory trees and understory saplings after mountain pine beetle attack in central British Columbia, Forest Ecol. Manag., 310, 348-356, 2013.

Heath, R. and Alfaro, R. I.: Growth response in a Douglasfir/lodgepole pine stand after thinning of lodgepole pine by the mountain pine beetle: A case study, Journal of the Entomological Society of British Columbia, 87, 16-21, 1990.

Hicke, J. A., Allen, C. D., Desai, A. R., Dietze, M. C., Hall, R. J., Hogg, E. H. T., Kashian, D. M., Moore, D., Raffa, K. F., Sturrock, R. N., and Vogelmann, J.: Effects of Biotic Disturbances on Forest Carbon Cycling in the United States and Canada, Glob. Change Biol., 18, 7-34, 2012a.

Hicke, J. A., Johnson, M. C., Hayes, J. L., and Preisler, H. K.: Effects of bark beetle-caused tree mortality on wildfire, Forest Ecol. Manag., 271, 81-90, 2012b.

Joos, F., Roth, R., Fuglestvedt, J. S., Peters, G. P., Enting, I. G., von Bloh, W., Brovkin, V., Burke, E. J., Eby, M., Edwards, N. R., Friedrich, T., Frölicher, T. L., Halloran, P. R., Holden, P. B., Jones, C., Kleinen, T., Mackenzie, F. T., Matsumoto, K., Meinshausen, M., Plattner, G.-K., Reisinger, A., Segschneider, J., Shaffer, G., Steinacher, M., Strassmann, K., Tanaka, K., Timmermann, A., and Weaver, A. J.: Carbon dioxide and climate impulse response functions for the computation of greenhouse gas metrics: a multi-model analysis, Atmos. Chem. Phys., 13, 27932825, doi:10.5194/acp-13-2793-2013, 2013.
Kashian, D. M., Jackson, R. M., and Lyons, H. D.: Forest structure altered by mountain pine beetle outbreaks affects subsequent attack in a Wyoming lodgepole pine forest, USA, Can. J. Forest Res., 41, 2403-2412, 2011.

Kashian, D. M., Romme, W. H., Tinker, D. B., Turner, M. G., and Ryan, M. G.: Postfire changes in forest carbon storage over a 300-year chronosequence of Pinus contorta-dominated forests, Ecol. Monogr., 83, 49-66, 2013.

Klutsch, J. G., Negrón, J. F., Costello, S. L., Rhoades, C. C., West, D. R., Popp, J., and Caissie, R.: Stand characteristics and downed woody debris accumulations associated with a mountain pine beetle (Dendroctonus ponderosae Hopkins) outbreak in Colorado, Forest Ecol. Manag., 258, 641-649, 2009.

Kucharik, C. J., Foley, J. A., Delire, C., Fisher, V. A., Coe, M. T., Lenters, J. D., Young-Molling, C., Ramankutty, N., Norman, J. M., and Gower, S. T.: Testing the performance of a dynamic global ecosystem model: Water balance, carbon balance, and vegetation structure, Global Biogeochem. Cy., 14, 795-825, 2000.

Kucharik, C. J., Barford, C. C., El Maayar, M., Wofsy, S. C., Monson, R. K., and Baldocchi, D. D.: A multiyear evaluation of a Dynamic Global Vegetation Model at three AmeriFlux forest sites: vegetation structure, phenology, soil temperature, and $\mathrm{CO}_{2}$ and $\mathrm{H}_{2} \mathrm{O}$ vapor exchange, Ecol. Model., 196, 1-31, 2006.

Kurz, W. A., Dymond, C. C., Stinson, G., Rampley, G. J., Neilson, E. T., Carroll, A. L., Ebata, T., and Safranyik, L.: Mountain pine beetle and forest carbon feedback to climate change, Nature, 452, 987-990, 2008.

Kurz, W. A., Dymond, C. C., White, T. M., Stinson, G., Shaw, C. H., Rampley, G. J., Smyth, C., Simpson, B. N., Neilson, E. T., Trofymow, J. A., Metsaranta, J., and Apps, M. J.: CBM-CFS3: A model of carbon-dynamics in forestry and land-use change implementing IPCC standards, Ecol. Model., 220, 480-504, 2009.

Landry, J.-S. and Matthews, H. D.: Non-deforestation fire vs. fossil fuel combustion: the source of $\mathrm{CO}_{2}$ emissions affects the global carbon cycle and climate responses, Biogeosciences, 13, 2137 2149, doi:10.5194/bg-13-2137-2016, 2016.

Landry, J.-S. and Ramankutty, N.: Carbon Cycling, Climate Regulation, and Disturbances in Canadian Forests: Scientific Principles for Management, Land, 4, 83-118, 2015.

Landry, J.-S., Price, D. T., Ramankutty, N., Parrott, L., and Matthews, H. D.: Implementation of a Marauding Insect Module (MIM, version 1.0) in the Integrated BIosphere Simulator (IBIS, version 2.6b4) dynamic vegetation-land surface model, Geosci. Model Dev., 9, 1243-1261, doi:10.5194/gmd-9-12432016, 2016.

Le Quéré, C., Moriarty, R., Andrew, R. M., Peters, G. P., Ciais, P., Friedlingstein, P., Jones, S. D., Sitch, S., Tans, P., Arneth, A., Boden, T. A., Bopp, L., Bozec, Y., Canadell, J. G., Chini, L. P., Chevallier, F., Cosca, C. E., Harris, I., Hoppema, M., Houghton, R. A., House, J. I., Jain, A. K., Johannessen, T., Kato, E., Keeling, R. F., Kitidis, V., Klein Goldewijk, K., Koven, C., Landa, C. S., Landschützer, P., Lenton, A., Lima, I. D., Marland, G., Mathis, J. T., Metzl, N., Nojiri, Y., Olsen, A., Ono, T., Peng, S., Peters, W., Pfeil, B., Poulter, B., Raupach, M. R., Regnier, P., Rödenbeck, C., Saito, S., Salisbury, J. E., Schuster, U., Schwinger, J., Séférian, R., Segschneider, J., Steinhoff, T., Stocker, B. D., Sutton, A. J., Takahashi, T., Tilbrook, B., van der Werf, G. R., Viovy, N., Wang, Y.-P., Wanninkhof, R., Wiltshire, A., and Zeng, 
N.: Global carbon budget 2014, Earth Syst. Sci. Data, 7, 47-85, doi:10.5194/essd-7-47-2015, 2015.

Lee, X., Goulden, M. L., Hollinger, D. Y., Barr, A., Black, T. A., Bohrer, G., Bracho, R., Drake, B., Goldstein, A., Gu, L., Katul, G., Kolb, T., Law, B. E., Margolis, H., Meyers, T., Monson, R., Munger, W., Oren, R., Paw U, K. T., Richardson, A. D., Schmid, H. P., Staebler, R., Wofsy, S., and Zhao, L.: Observed increase in local cooling effect of deforestation at higher latitudes, Nature, 479, 384-387, 2011.

Lemprière, T. C., Kurz, W. A., Hogg, E. H., Schmoll, C., Rampley, G. J., Yemshanov, D., Mckenney, D. W., Gilsenan, R., Beatch, A., Blain, D., Bhatti, J. S., and Krcmar, E.: Canadian boreal forests and climate change mitigation, Environ. Rev., 21, 293321,2013

Lenters, J. D., Coe, M. T., and Foley, J. A.: Surface water balance of the continental United States, 1963-1995: Regional evaluation of a terrestrial biosphere model and the NCEP/NCAR reanalysis, J. Geophys. Res., 105, 22393-22425, 2000.

Liu, S., Bond-Lamberty, B., Hicke, J. A., Vargas, R., Zhao, S., Chen, J., Edburg, S. L., Hu, Y., Liu, J., McGuire, A. D., Xiao, J., Keane, R., Yuan, W., Tang, J., Luo, Y., Potter, C., and Oeding, J.: Simulating the impacts of disturbances on forest carbon cycling in North America: Processes, data, models, and challenges, J. Geophys. Res., 116, G00K08, doi:10.1029/2010JG001585, 2011.

Liu, Z., Notaro, M., Kutzbach, J., and Liu, N.: Assessing Global Vegetation-Climate Feedbacks from Observations, J. Climate, 19, 787-814, 2006.

Maness, H., Kushner, P. J., and Fung, I.: Summertime climate response to mountain pine beetle disturbance in British Columbia, Nat. Geosci., 6, 65-70, 2013.

Mathys, A., Black, T. A., Nesic, Z., Nishio, G., Brown, M., Spittlehouse, D. L., Fredeen, A. L., Bowler, R., Jassal, R. S., Grant, N. J., Burton, P. J., Trofymow, J. A., and Meyer, G.: Carbon balance of a partially harvested mixed conifer forest following mountain pine beetle attack and its comparison to a clear-cut, Biogeosciences, 10, 5451-5463, doi:10.5194/bg-10-5451-2013, 2013.

Mikkelson, K. M., Bearup, L. A., Maxwell, R. M., Stednick, J. D., McCray, J. E., and Sharp, J. O.: Bark beetle infestation impacts on nutrient cycling, water quality and interdependent hydrological effects, Biogeochemistry, 115, 1-21, 2013.

Moorcroft, P. R.: How close are we to a predictive science of the biosphere?, Trends Ecol. Evol., 21, 400-407, 2006.

Myhre, G., Highwood, E. J., Shine, K. P., and Stordal, F.: New estimates of radiative forcing due to well mixed greenhouse gases, Geophys. Res. Lett., 25, 2715-2718, 1998.

Myhre, G., Shindell, D., Bréon, F.-M., Collins, W., Fuglestvedt, J., Huang, J., Koch, D., Lamarque, J.-F., Lee, D., Mendoza, B., Nakajima, T., Robock, A., Stephens, G., Takemura, T., and Zhang, H.: Anthropogenic and Natural Radiative Forcing, in: Climate Change 2013: The Physical Basis, Contribution of Working Group I to the Fifth Assessment Report of the International Panel on Climate Change, edited by: Stocker, T. F., Qin, D., Plattner, G. K., Tignor, M., Allen, S. K., Boschung, J., Nauels, A., Xia, Y., Bex, V., and Midgley, P., Cambridge University Press, Cambridge, UK and New York, USA, 659-740, 2013.

Nealis, V. G. and Cooke, B. J.: Risk assessment of the threat of mountain pine beetle to Canada's boreal and eastern pine forests. Canadian Council of Forest Ministers, Forest Pest Working Group, 27 pp., 2014.

New, M., Hulme, M., and Jones, P.: Representing TwentiethCentury Space-Time Climate Variability, Part I: Development of a 1961-1990 Mean Monthly Terrestrial Climatology, J. Climate, 12, 829-586, 1999.

NRCan: Trees, insects and diseases of Canada's forests, Mountain pine beetle, Natural Resources Canada, available at: http://tidcf. nrcan.gc.ca/en/insects/factsheet/2816 (last access: 24 December 2014), 2012.

O'Halloran, T. L., Law, B. E., Goulden, M. L., Wang, Z., Barr, J. G., Schaaf, C., Brown, M., Fuentes, J. D., Göckede, M., Black, A., and Engel, V.: Radiative forcing of natural forest disturbances, Glob. Change Biol., 18, 555-565, 2012.

Patriquin, M., Heckbert, S., Nickerson, C., Spence, M., and White, B.: Regional Economic Implications of the Mountain Pine Beetle Infestation in the Northern Interior Forest Region of British Columbia. Mountain Pine Beetle Initiative working paper 20053, Canadian Forest Service, Pacific Forestry Centre, Victoria, British Columbia, 58 pp., 2005.

Pelz, K. A. and Smith, F. W.: How will aspen respond to mountain pine beetle? A review of literature and discussion of knowledge gaps, Forest Ecol. Manag., 299, 60-69, 2013.

Pfeifer, E. M., Hicke, J. A., and Meddens, A. J. H.: Observations and modeling of aboveground tree carbon stocks and fluxes following a bark beetle outbreak in the western United States, Glob. Change Biol., 17, 339-350, 2011.

Pollard, D. and Thompson, S. L.: Use of a land-surface-transfer scheme (LSX) in a global climate model: the response to doubling stomatal resistance, Global Planet. Change, 10, 129-161, 1995.

Pugh, E. and Small, E.: The impact of pine beetle infestation on snow accumulation and melt in the headwaters of the Colorado River, Ecohydrology, 5, 467-477, 2012.

Purves, D. and Pacala, S.: Predictive models of forest dynamics, Science, 320, 1452-1453, 2008.

Reed, D. E., Ewers, B. E., and Pendall, E.: Impact of mountain pine beetle induced mortality on forest carbon and water fluxes, Environ. Res. Lett., 9, 105004, doi:10.1088/1748-9326/9/10/105004, 2014.

Romme, W. H., Knight, D. H., and Yavitt, J. B.: Mountain Pine Beetle Outbreaks in the Rocky Mountains: Regulators of Primary Productivity?, Am. Nat., 127, 484-494, 1986.

Safranyik, L. and Carroll, A. L.: The biology and epidemiology of the mountain pine beetle in lodgepole pine forests, in: The Mountain Pine Beetle: A Synthesis of Biology, Management, and Impacts on Lodgepole Pine, edited by: Safranyik, L. and Wilson, B., Natural Resources Canada, Victoria, Canada, 3-66, 2006.

Seidl, R., Rammer, W., Jäger, D., and Lexer, M. J.: Impact of bark beetle (Ips typographus L.) disturbance on timber production and carbon sequestration in different management strategies under climate change, Forest Ecol. Manag., 256, 209-220, 2008.

Seidl, R., Fernandes, P. M., Fonseca, T. F., Gillet, F., Jönsson, A. M., Merganičová, K., Netherer, S., Arpaci, A., Bontemps, J.-D., Bugmann, H., González-Olabarria, J. R., Lasch, P., Meredieu, C., Moreira, F., Schelhaas, M.-J., and Mohren, F.: Modelling natural disturbances in forest ecosystems: a review, Ecol. Model., 222, 903-924, 2011. 
Shell, K. M., Kiehl, J. T., and Shields, C. A.: Using the Radiative Kernel Technique to Calculate Climate Feedbacks in NCAR's Community Atmospheric Model, J. Climate, 21, 2269-2282, 2008.

Soden, B. J., Held, I. M., Colman, R., Shell, K. M., Kiehl, J. T., and Shields, C. A.: Quantifying Climate Feedbacks Using Radiative Kernels, J. Climate, 21, 3504-3520, 2008.

Stone, W. E. and Wolfe, M. L.: Responses of understory vegetation to variable tree mortality following a mountain pine beetle epidemic in lodgepole pine stands in northern Utah, Vegetatio, 122, 1-12, 1996.

Stuart-Haëntjens, E. J., Curtis, P. S., Fahey, R. T., Vogel, C. S., and Gough, C. M.: Net primary production of a temperate deciduous forest exhibits a threshold response to increasing disturbance severity, Ecology, 96, 2478-2487, 2015.
Vanderhoof, M., Williams, C. A., Shuai, Y., Jarvis, D., Kulakowski, D., and Masek, J.: Albedo-induced radiative forcing from mountain pine beetle outbreaks in forests, south-central Rocky Mountains: magnitude, persistence, and relation to outbreak severity, Biogeosciences, 11, 563-575, doi:10.5194/bg-11-563-2014, 2014.

Wallace, J. M. and Hobbs, P. V.: Atmospheric Science: An Introductory Survey, 2nd Edition, Academic Press, Burlington, USA, 2006.

Walton, A.: Provincial-Level Projection of the Current Mountain Pine Beetle Outbreak: Update of the infestation projection based on the Provincial Aerial Overview Surveys of Forest Health conducted from 1999 through 2012 and the BCMPB model (year 10), BC Forest Service, 2013. 